\title{
A basic guide for sampling and preparation of extant and fossil bones for histological studies
}

\author{
IGNACIO A. CERDA ${ }^{1}$ \\ MARÍA E. PEREYRA ${ }^{2}$ \\ MARIANA GARRONE ${ }^{3}$ \\ DENIS PONCE ${ }^{1}$ \\ TAMARA G. NAVARRO ${ }^{1}$ \\ ROMINA GONZÁLEZ ${ }^{4}$ \\ MARIANO MILITELLO 2 \\ CARLOS A. LUNA ${ }^{4}$ \\ JUAN M. JANNELLO5
}

1. CONICET-Instituto de Investigación en Paleobiología y Geología, Museo Carlos Ameghino, Universidad Nacional de Río Negro. Belgrano 1700, Paraje Pichi Ruca (predio Marabunta), 8300 Cipolletti, Río Negro, Argentina.

2. CONICET-División Paleontología Vertebrados, Facultad de Ciencias Naturales y Museo, Universidad Nacional de La Plata. Av. 122 y 60, B1900FWA La Plata, Buenos Aires, Argentina.

3. CONICET-Instituto Geológico del Sur, Departamento de Geología, Universidad Nacional del Sur. Av. Alem 1253, 8000 Bahía Blanca, Buenos Aires, Argentina.

4. CONICET-Centro de Ecología Aplicada del Litoral. Ruta 5 (km 5.2), 3400 Corrientes, Corrientes, Argentina.

5. University of Cape Town, Department of Biological Sciences. Private Bag X3, 7700 Rhodes Gift, South Africa.

Recibido: 7 de febrero 2020 - Aceptado: 7 de abril 2020

Para citar este artículo: Ignacio A. Cerda, María E. Pereyra, Mariana Garrone, Denis Ponce, Tamara G. Navarro, Romina González, Mariano Militello, Carlos A. Luna, and Juan M. Jannello (2020). A basic guide for sampling and preparation of extant and fossil bones for histological studies. Publicación Electrónica de la Asociación Paleontológica Argentina 20 (1): $15-28$.

Link a este artículo: http://dx.doi.org/10.5710/PEAPA.07.04.2020.314

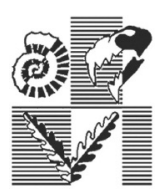

ISSN 2469-0228

\section{Asociación Paleontológica Argentina}

Maipú $6451^{\circ}$ piso, C1006ACG, Buenos Aires

República Argentina

Tel/Fax (54-11) 4326-7563

Web: www.apaleontologica.org.ar 


\title{
A BASIC GUIDE FOR SAMPLING AND PREPARATION OF EXTANT AND FOSSIL BONES FOR HISTOLOGICAL STUDIES
}

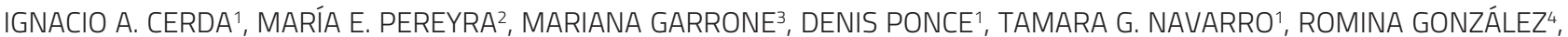 \\ MARIANO MILITELLO², CARLOS A. LUNA ${ }^{4}$, AND JUAN M. JANNELLO5
}

\begin{abstract}
'CONICET-Instituto de Investigación en Paleobiología y Geología, Museo Carlos Ameghino, Universidad Nacional de Río Negro. Belgrano 1700, Paraje Pichi Ruca (predio Marabunta),8300 Cipolletti, Río Negro, Argentina.nachocerda6@gmail.com; denispunrn@yahoo.com.ar; 89tamaranavarro@gmail.com ${ }^{2}$ CONICET-División Paleontología Vertebrados, Facultad de Ciencias Naturales y Museo, Universidad Nacional de La Plata. Av. 122 y 60, B1900FWA La Plata, Buenos Aires, Argentina.m.eugenia.pereyra@gmail.com; marianomilitello@hotmail.com

${ }^{3}$ CONICET-Instituto Geológico del Sur, Departamento de Geología, Universidad Nacional del Sur. Av. Alem 1253, 8000 Bahía Blanca, Buenos Aires, Argentina. garrone.mariana@gmail.com

${ }^{4}$ CONICET-Centro de Ecología Aplicada del Litoral. Ruta 5 (km 5.2),3400 Corrientes, Corrientes, Argentina. romigonzl95@gmail.com; carlosaluna@hotmail.com 5University of Cape Town, Department of Biological Sciences. Private Bag X3, 7700 Rhodes Gift, South Africa. marcosjannello@hotmail.com
\end{abstract}

\begin{abstract}
The study of bone microstructure of fossil vertebrates (i.e., paleohistology) has demonstrated to be a very important source of paleobiological information. Paleohistological studies are based on the standardized analysis of petrographic thin sections. Although the development of new technologies (e.g., microtomography) have provided non-destructive procedures for the study the fossil tissues, thin sections are still the main source of information in paleohistology. In this contribution, we provide a detailed protocol for sampling and thin-sectioning preparation of bone tissue from both fossil and extant vertebrates. We describe the most common procedures for sampling and also some particularities related to variations in equipment and sampling techniques. The main goal of this contribution is to offer an alternative protocol for research teams of recent formation and/or with limited funding.
\end{abstract}

Key words. Paleohistology. Technique. Thin section. Protocol.

Resumen. GUÍA BÁSICA PARA EL MUESTREO Y PREPARADO DE HUESOS ACTUALES Y FÓSILES PARA ESTUDIOS HISTOLÓGICOS. EI EStUdio de la microestructura ósea de vertebrados fósiles (i.e., paleohistología) ha demostrado ser una importante fuente de información paleobiológica. Los estudios paleohistológicos están basados en análisis estandarizados de secciones delgadas petrográficas. A pesar de que el desarrollo de nuevas tecnologías (e.g., microtomografía) ha proporcionado procedimientos no destructivos para el estudio de tejidos fósiles, las secciones delgadas continúan siendo la principal fuente de información paleohistológica. En esta contribución, proporcionamos un protocolo detallado para el muestreo y preparación de secciones delgadas de huesos de vertebrados tanto fósiles como vivientes. Se describen los procedimientos más comunes para la obtención de las muestras y se plantean diferencias particulares, las cuales están relacionadas con las variaciones del equipamiento y las técnicas de muestreo. El objetivo principal de esta contribución es proveer un protocolo alternativo para laboratorios en formación y/o con financiamiento limitado.

Palabras clave. Paleohistología. Técnica. Sección delgada. Protocolo.

Paleohistology is the discipline that deals with the analysis and interpretation of fossil tissues. In the particular case of vertebrates, histological information is obtained mainly from bones and teeth. Since this discipline has proved to be a major source of paleobiological information, the number of paleohistological studies has increased notably during the last decades. Bone microstructure provides a direct record of ontogenetic growth that gives clues concerning various aspects of vertebrate biology, including growth rates (e.g.,
Chinsamy, 1995; Erickson et al., 2001; Padian et al., 2004; Lehman and Woodward, 2008), Iongevity (e.g., Chinsamy, 1990, 1993; Varricchio, 1993; Curry,1999), age at maturity (e.g., Varricchio, 1993; Sander, 2000; Klein and Sander, 2007; Lee and Werning, 2008; Marín-Moratalla et al., 2013), adult size (e.g., Sander et al., 2006; Klein and Sander, 2007; Stein et al., 2010; Company, 2011), and ontogenetic stages and timing of sexual maturity (Sander, 2000; Erickson et al., 2007; Klein and Sander, 2008; Lee and Werning, 2008; 
Hayashi et al., 2009), among other features.

Although new technologies (e.g., microtomography) have provided non-destructive procedures for the study the fossil tissues (e.g., Dupret et al., 2010; Sánchez et al., 2013), thin sections remain as the main source of paleohistological information. An important advantage of this technique relies on the relative accessibility of equipment and supplies. The basic protocols for thin section preparation of fossil bones have been previously outlined (e.g., Enlow and Brown, 1956; Chinsamy and Raath, 1992); furthermore, they are usually included in the 'Methodology' section of paleohistological publications (e.g., Steel, 2008; Werning, 2012; MartínezMaza et al., 2014). To date, the most complete survey about thin section preparation of fossil bones was Lamm's (2013), in a work that includes not only an extensive guide for processing different types of elements, but also a detailed list of all the supplies and equipment used during the entire procedure. The abovementioned contributions employ specific equipment (e.g., Buehler Isomet low speed saw) which may be difficult to obtain for laboratories and research teams in early stages of formation (e.g., with restricted funding).

Here we provide a detailed protocol for sampling and thin section preparation of bone from both fossil and extant vertebrates. As pointed by Chinsamy and Raath (1992), all the published procedures share a common core of processes. We describe those common procedures and additionally discuss some particularities related to variations in equipment and sampling techniques. The main goal of this contribution is to offer an alternative protocol for research teams in formation and/or with limited funding. Since these limitations frequently involve a lack of adequate equipment, the procedure outlined here does not purport to be optimal. However, it has been demonstrated to be very useful for the preparation of thin sections from both fossil and extant specimens. The protocol here provided has been used during the last three years in the Paleohistological Laboratory of the Museo Provincial Carlos Ameghino (MPCA, Cipolletti, Province of Río Negro, Argentina). The procedure here described has also been employed for non-decalcified bones of extant vertebrates (including human bones from archaeological sites), eggshells and fossil wood.

\section{MATERIALS AND METHODS Materials}

The procedure involves the use of specific equipment and consumables, all of them used in our laboratory. The equipment includes: mini Dremel rotatory tool, hot air gun, electric power drill, homemade high speed diamond cutoff saw, homemade lapidary grinder, homemade lapidary slabsaw, and electric hot plate for laboratory. The consumable supplies comprise: two parts epoxy putty, clay, silicone rubber, Dim Clay, plaster, white powder resin, water soluble oil, coarse aluminum foil paper, epoxy resin DICAST LY 554 and 867 with their respective catalysts (DICURE HY 554 and 867); plastic syringes, cyanoacrylate, alcohol, ultraviolet curing glue, wet sanding papers (100, 220, 320 grit), silicon carbide and aluminum oxide abrasive powders $(80,120,220,400$ and 800 grit), 3 mm glasses and disposable containers.

\section{Procedure}

Sampling. Although the main steps for thin section preparation are roughly invariant, there are several alternatives at each step that are determined by the nature of the sectioned specimen. One of the most important parameters in this regard is the size of the latter. Here we define three main sizes taking into account the longest diameter of the sectioned surface: small (less than $10 \mathrm{~mm}$ ), medium (between 10 and $50 \mathrm{~mm}$ ) and large (more than $50 \mathrm{~mm}$ ). It must be noted that these predefined sample diameters do not always correspond to the size of the element. For example, a small or medium sized sample can be obtained from a large bone, since in some cases only a fraction of the circumference of the bone can be sampled. Regarding the sampling technique used in a particular specimen, the first issue that must be address involves the irreversible modification that will be done to the element. For example, if the entire bone is a diminutive element, complete destruction of the same is actually inevitable. In this case, in addition to previously obtaining measurements and photographic records of the bone, a complete mold and cast of the same should be performed (see 'Molding and casting' section). For larger bones (i.e., larger than $20 \mathrm{~mm}$ approximately), a small sample can be obtained for thin sectioning, leaving most of the original piece intact. However, if the analysis is focused 
on intraelemental histological variation, serial sectioning of the sample will be necessary and the specimen will be destroyed. In such a case, a mold and cast of the whole bone should be made. In some instances, the natural fractures of the bones that have been previously glued together can be used for sampling. The application of heat with a hot air gun to the fractured sites softens the glue, which eventually peels off (in some cases, it is necessary to use a chisel to force the breaking). This procedure has been very useful for sampling in old collections, since the original glue can be easily removed with heat. The usage of a hot air gun to obtain samples is limited by the location of the original fracture, the shape of the fractures, and the products used for gluing the parts. The size of the sample obtained from this or other methods is also very important. For example, while the extraction (and restoration) of a complete block of 15 $\mathrm{mm}$ thickness from the entire midshaft of a large bone (e.g., sauropod long bone) will not considerably affect its morphology, such a procedure would strongly alter a small element (e.g., long bone of a micro-mammal). Hence, although no "optimal" size for sampling can be defined, researchers should endeavor to affect the original structure of the element as little as possible.

For those bones in which natural fractures are absent or distant from the desired sampling place, one or two mechanical sections must be done. This procedure varies according to the size of the bone and the location of sample extraction. If it were possible to transport the bone to the sectioning laboratory, the ideal procedure involves using a diamond cut-off saw. For small or medium size bones (under $10 \mathrm{~cm}$ diameter approximately), our own laboratory is equipped with a homemade high-speed diamond cut-off saw (Fig. 1). It has a standardized armored engine of 0.75 HP and 2800 RPM. This machine was built using aluminum alloy that prevents vibrations and is equipped with a thin diamond-edged MK-303 lapidary blade $(20$ cm diameter, $0.5 \mathrm{~mm}$ thickness). During cutting, the lapidary blade is cooled and lubricated with water-soluble oil. If the sample comes from larger specimens (more than $10 \mathrm{~cm}$ diameter), a slab saw is used to obtain it. Although the laboratory is the ideal place for sampling, this procedure is commonly performed in collection facilities, where an electric diamond cut-off saw is usually unavailable. In these cases, samples from small or medium sized bones can be extracted using a Dremel rotatory tool equipped with a thin diamond-edged saw. We usually use $60 \mathrm{~mm}$-diameter blades. In some instances, if a Dremel tool is not available, samples can be extracted using a hand saw. Although the latter procedure is more time-consuming and also limited by the hardness
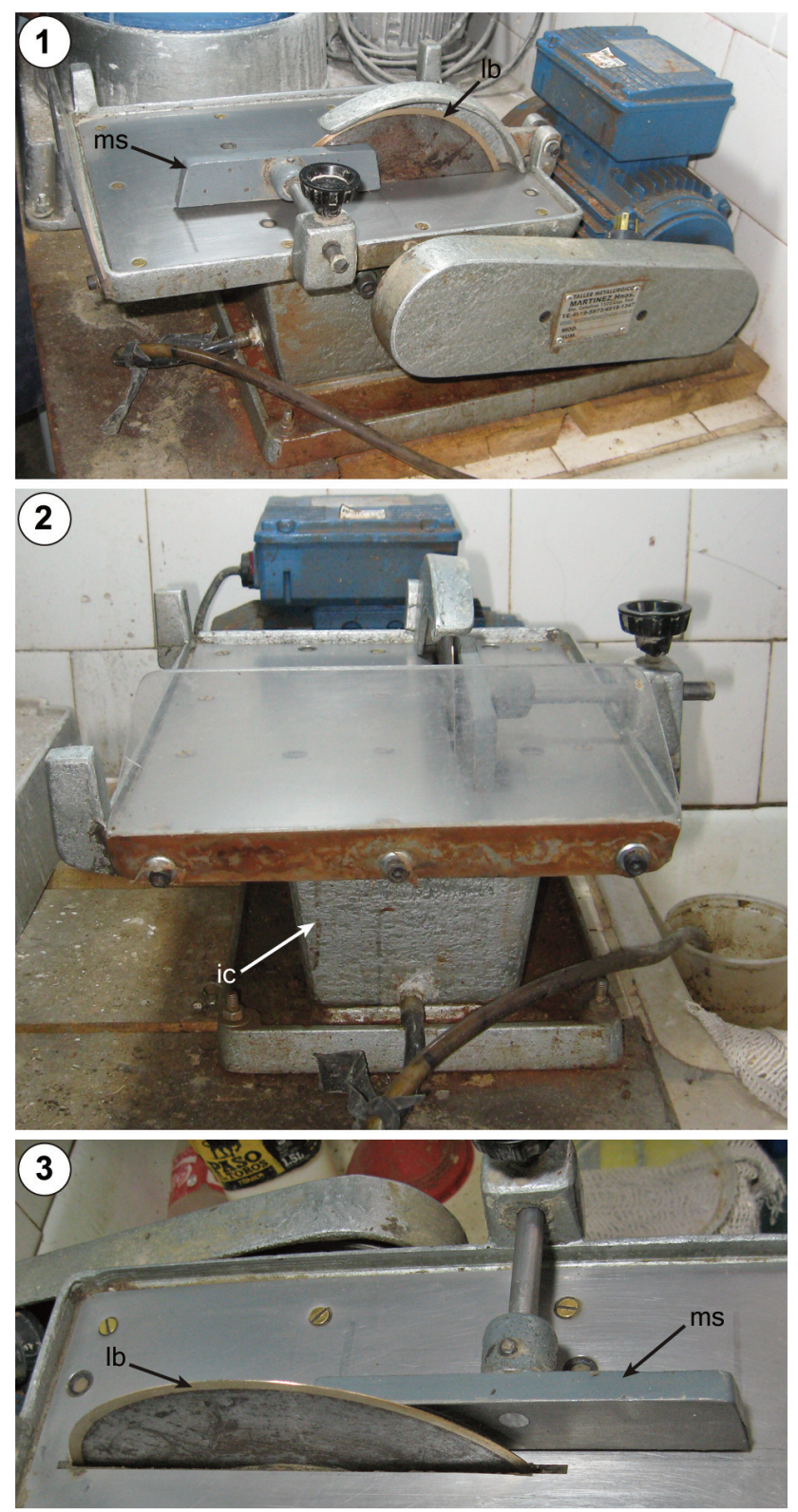

Figure 1. Homemade high-speed diamond cut-off saw. The machine is built from aluminum alloy and equipped with a thin diamond-edged lapidary blade (Ib). The lapidary blade is cooled and lubricated with soluble oil contained in an inner receptacle (ic). A movable support (ms) is aligned with the lapidary blade. 
and fragility of the piece, it has been successfully employed in some instances (e.g., Luna et al., 2018). When the element to be sampled is too large to allow appropriate usage of a Dremel tool, an alternative procedure involves the extraction of a small core using a drill. In contrast with the previously discussed cases that entail the extraction of a complete section of the sample (e.g., long bone shaft), in this case only small portions can be obtained. Although the histological in-
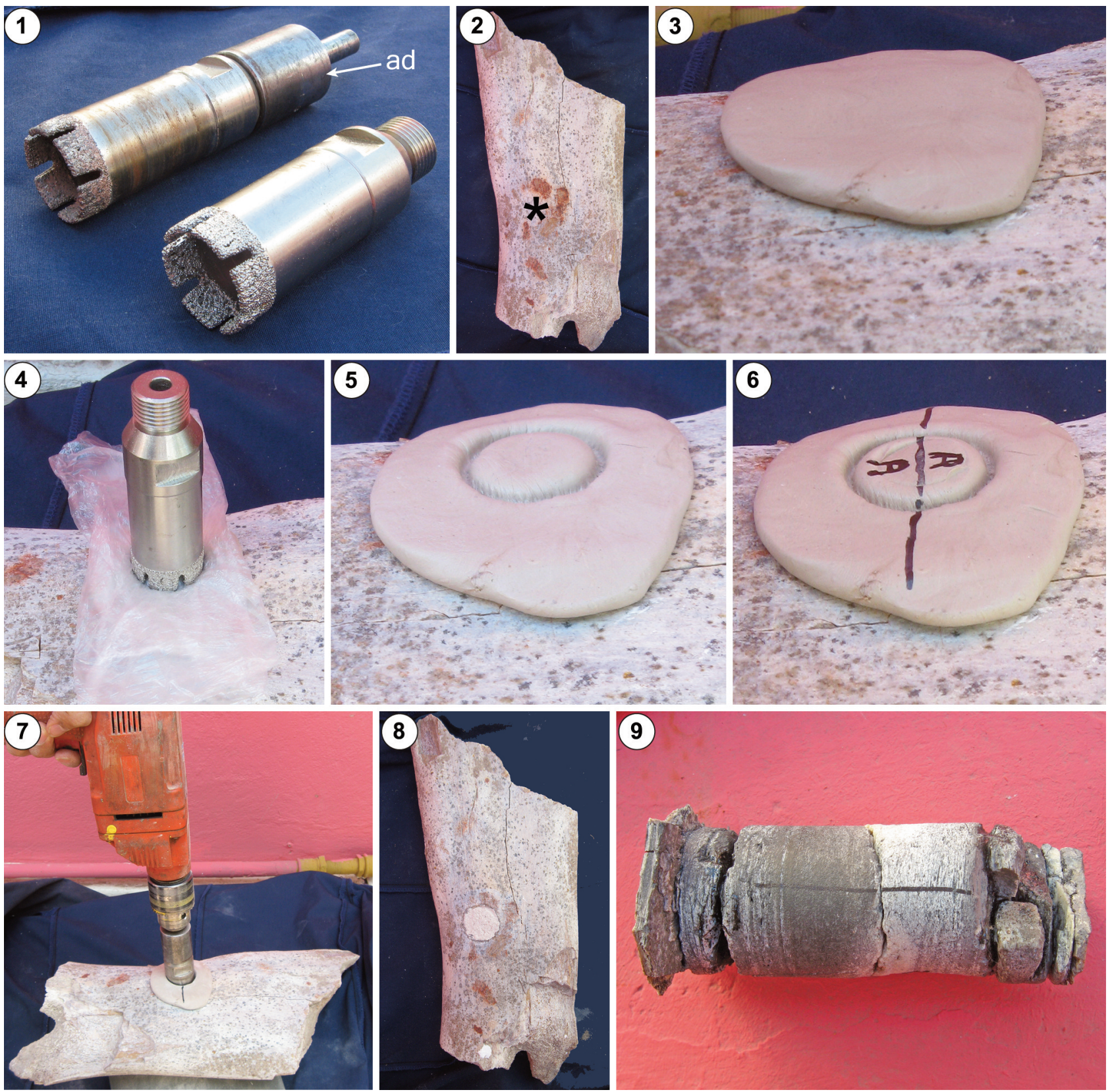

Figure 2. Sample obtainment using drill coring. 1, $30 \mathrm{~mm}$ drill bits. One of the bits is shown with the adapter for electric drill (ad). 2, Femur shaft of an undetermined titanosaur showing the location of the sampling (asterisk). 3, The surface is covered with two-component epoxy putty. 4, Before consolidation of the putty, it is marked with the bit. A fragment of polyethylene bag is used to cover the bit and avoid undesirable mess. 5-6, The marked putty is labeled indicating the position of the sample (anterior in this case) and the plane of sectioning. 7, The sample is obtained using the bit mounted on an electric drill. 8, Restored element before sampling. The hole left by the drill coring has been filled with plaster. 9, Complete sample obtained. 
formation that can be gained from cores is much less when compared with complete sections, this procedure is the only available sampling method in many cases. Furthermore, since this methodology involves just a small intervention of the sample, it is also the only procedure allowed by collection managers in some cases. The drill coring technique was originally developed by Sander (2000) for sampling long bones of sauropod dinosaurs from the Tendaguru Formation in Tanzania. The basic procedure involves the extraction of bone cores using diamond studded drill bits mounted on a domestic power drill, which is stabilized in a drill press (Sander, 2000; Stein and Sander, 2009). More recent studies by Woodruff et al. (2017) and Mukherjee (2018) have proposed some modifications to this basic procedure, which are mainly related to the type of coring bit and the inclusion of a device for support of the power drill and bone during the sampling. To acquire bone cores, we follow the main process proposed by Sander (2000) with some particularities (Fig. 2). We use $30 \mathrm{~mm}$ diameter bits with their ends covered with diamond grit. The bit length allows it to penetrate up to $50 \mathrm{~mm}$ deep into the bone. Unlike previous contributions (i.e., Sander, 2000; Stein and Sander, 2009; Woodruff et al., 2017; Mukherjee, 2018), we do not employ a drill press. Instead, we cover the site from which the core will be obtained with a thin (around $5 \mathrm{~mm}$ thick) layer of two-part epoxy putty. Then, the end of the bit is pressed over the surface of the putty layer before the latter hardens completely. A fragment of polyethylene bag is used to cover the bit in order to prevent it from getting dirty. Once the putty hardens, the circular indentation left on it allows to stabilize the bite at the beginning of the drilling process. Such stabilization allows dispensing with the drill press, as the drill may be hand-held. This procedure eliminates the need to transport a drill press when visiting a collection. Since a drill press cannot be used in some instances in which the bone to sample is too large or mounted for exhibition, the use of a layer of putty is sometimes the only way to stabilize the coring. Another advantage of this procedure is that it minimizes the vibration transmitted from the drill press to the sampled bones. One disadvantage of this technique is related to the fact that the vibrations are received by the person holding the drill, who must try to maintain the latter always along the same trajectory, avoiding possible bending.
Whether the sample is obtained in a collection or in the laboratory, some important procedures must be performed on the bone before cutting. Since mechanical cutting usually tends to chip bone surfaces, it is necessary to build a protective layer. For this, we usually cover the bone surface with a layer of two parts epoxy putty (hereafter 'epoxy putty') (Fig. 3). Depending on the preservation of the bone surface, previous impregnation with cyanoacrylate or with epoxy resin diluted in alcohol (see 'Paint and Polish'
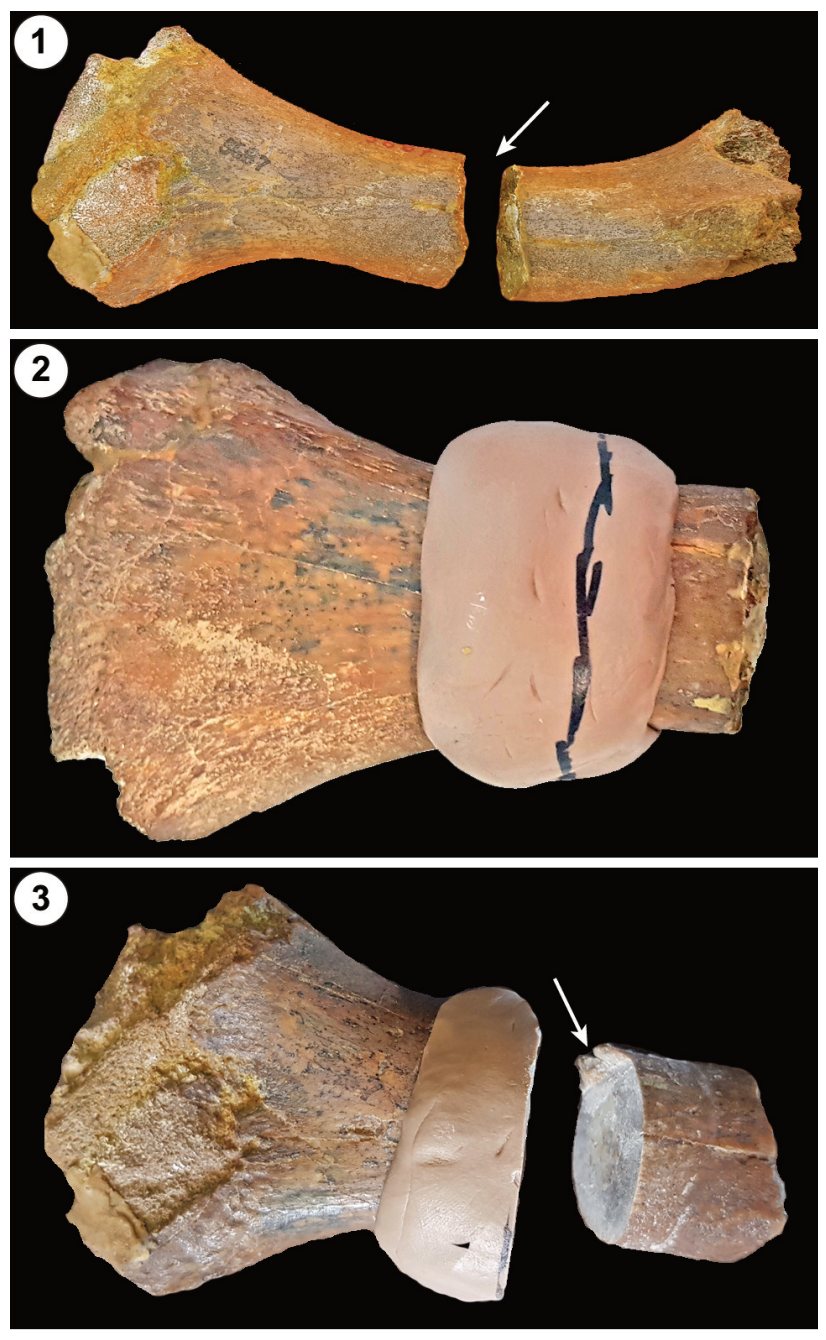

Figure 3. Sampling of a fossil crocodile long bone. 1, First, a natural fracture (arrow) previously glued together is peeled off with heat. 2 , A ring of epoxy putty is built around the site of sectioning. The same is labeled to indicate the plane of sectioning. 3, The epoxy putty of the sample obtained (right fragment) is removed using heat, and a mold and cast of the same can be made. A small broken edge (arrow) is generated to facilitate precise connection for the cast section. 
section) is often done. The thickness of the epoxy putty depends on the diameter of the sampled bone (i.e., larger elements need a higher amount of putty for stabilization). Before laying the epoxy putty, the surface of the bone should be cleaned with alcohol to ensure adequate adhesion of the putty. Since the epoxy putty becomes softer if heated, it can be easily removed after cutting. This characteristic is actually very important for the process, because a mold and a cast of the sampled fragment of bone must usually be done after cutting. When a mold and cast of the sample are not necessary (e.g., the entire element was molded before sampling), it is not necessary to remove the layer of epoxy putty. The only disadvantage of this procedure is that the putty generates a paste that needs to be washed away several times during the subsequent polishing. The sample can be cut once the protective layer attains the desired hardness (around 15 min.). The cutting process must be done only partially through the bone. A small uncut portion of the bone must be left to be broken out (Fig. 3.3). Such breakage will generate a jointed edge that will allow precise connection for the cast section.

Molding and casting. Once the bone sample is removed, a mold of silicone rubber and cast of acrylic resin are usually done to avoid the loss of important anatomical information in the samples, for future studies (e.g., total dimensions, distance between landmarks), as well as to ensure minimal intervention of the bone remains. We use silicone rubber to make molds because this product has particular qualities: low shrinkage, non-deformable, low viscosity and good flowability, fast setting (8 to 12 hrs., although accelerators may be added), high tear resistance and good elasticity, allowing easy de-molding and reproduction of details.

To make the molds, all the cracks and cavities must be first sealed with Dim Clay (hereafter 'clay') or epoxy putty, to avoid leakage of the silicone rubber into them. A single piece (i.e., one part) mold is produced if the specimen to be copied has a simple morphology. Conversely, if the morphology of the element is more complex, a two-piece mold is prepared.

Single piece mold (Fig. 4): in this case, a clay container is built and the sample is placed at the center of it, over a cone made also with clay (this will be the conduit through which the resin is poured). It is preferable to leave a space (e.g., 1 $\mathrm{cm}$ ) between the sample and the clay. The clay container must be attached to the surface since the silicone rubber can spill out of the container. The silicone rubber is prepared (100 parts silicone:4 parts catalyst) and poured from a distance; doing so produces a thin stream of silicon rubber that eliminates any large bubbles that may have formed and ensures good penetration on every detail of the element. The container must be filled until the silicone rubber fully convers the sample. Once the silicone rubber is cured, the whole is removed from the container and carefully de-molded.

Two-piece mold (Fig. 5): first, a clay container must be prepared. The base of the container is formed by a thick layer of clay. The sample is laid over this base, pressing against the same until half of the sample is covered with clay. Subsequently two clay cones are made and placed into contact with both the sample and the container margin (which must be on the same side). One of these sprues will serve to pour the resin while the other will prevent airlocks. In addition, some key holes must be made around the sample to allow proper fit of the two halves of the mold and also to avoid sliding of the two halves during the curing process. The walls of the container, which must surpass the upper border of the sample, are also made of clay. The silicone is prepared and poured in the same way as in the single piece mold. After the silicone has hardened completely, a protective layer of plaster is added to the side opposite to the sample. The plaster stabilizes the silicone mold maintaining its original shape. When the silicone is cured, the mold is turned over, and the clay is removed taking care that the sprues remain in place. A release agent is applied on the rubber to prevent the piece from sticking and then silicon rubber is poured onto the surface. When cured, the piece is carefully opened and de-molded.

We use acrylic resin (Ecocryl) to prepare the cast because this material is easy to handle, cures quickly (between 20 and $100 \mathrm{~min}$ ), presents high final hardness and does not shrink when hardening, which allows obtaining casts that are resistant and with all the details of the original material (Figs. 4.6 and 5.6). The resin is prepared according to the technical specifications (2.5 parts powder and 1 part hardening liquid) and applied by casting on the silicon mold. In the case of the two-piece molds, the two halves of the mold are placed together with the sprues oriented upwards and matching the key holes that were made into the mold 
halves. The two halves are secured with one or more rubber bands. Once the resin is finally hardened, the cast can be de-molding and painted.
Finally, the original sample is restored. For this, the cast is glued to the bone remain using a two-component epoxy glue or resin. If the latter is employed, it is necessary to use
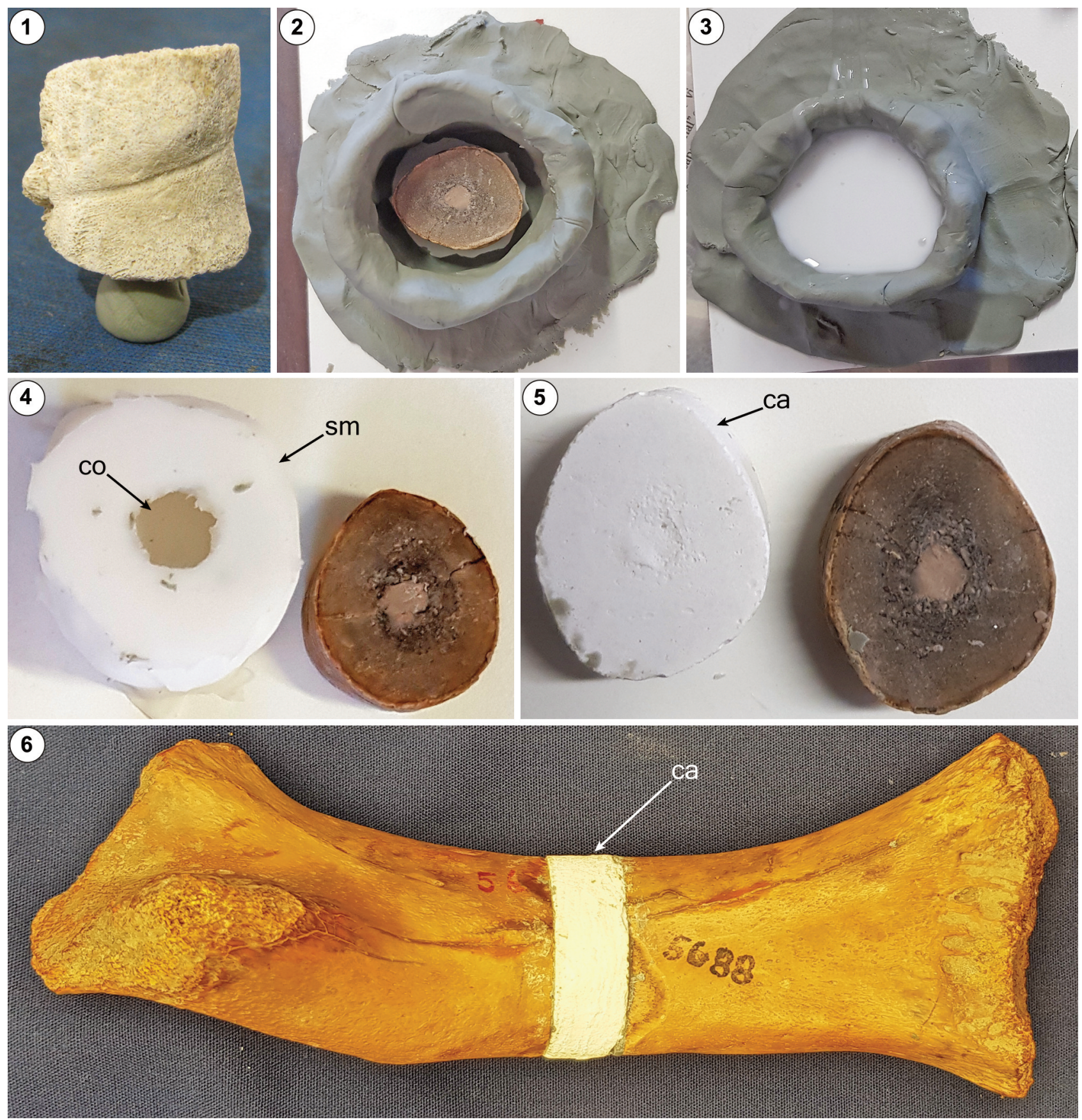

Figure 4. Single piece mold and casting. Whereas the sample in 1 corresponds to a fragment of fossil turtle plate, those shown in 2 to 6 correspond to a fossil crocodile long bone.1, The sample is placed over a small cone of clay (arrow). 2-3, A clay container is built around the sample and then filled with silicone rubber. 4, The sample is extracted from the silicone rubber mold (sm), which has a conduit (co) through which acrylic resin is poured. 5, A highly detailed cast (ca) made of acrylic resin is obtained from the silicone rubber mold. 6, The cast is glued with the original sample to maintain the original shape and size of the element. 
a press to keep the parts in proper position until it cures completely (12 hrs.).

Sample embedding. Once the sample is obtained, it is placed inside a container that allows complete embedding. Depending on the size and shape of the sample, a container that allows a rim of approximately $10 \mathrm{~mm}$ of resin around the entire piece is constructed (Fig. 6). The container is usually made with coarse aluminum foil paper. It is very important that the aluminum paper does not present any holes to avoid loss of resin during the embedding process. In some
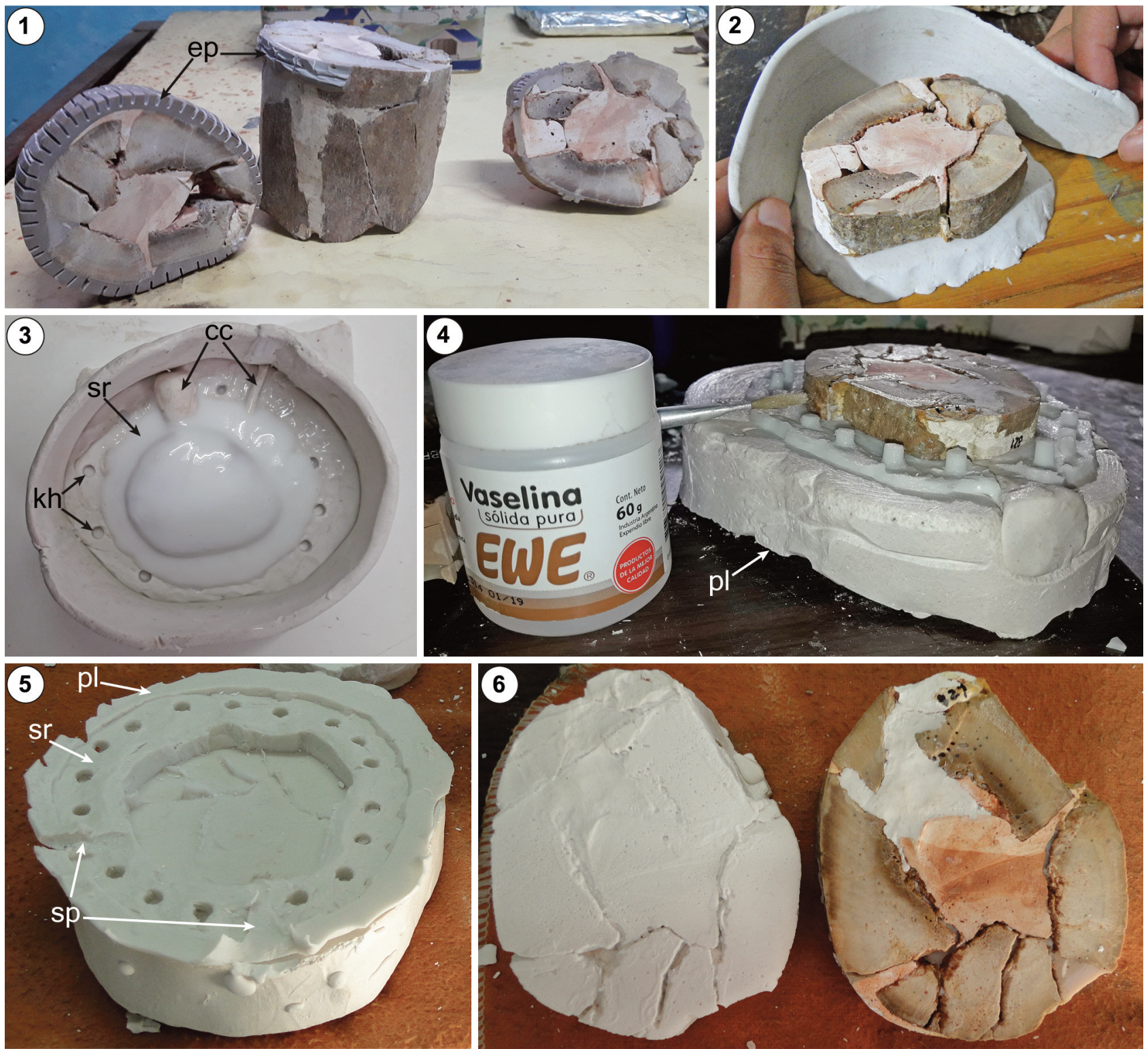

Figure 5. Two-piece mold and casting. 1, A complete section (left) is obtained from the femoral shaft of a titanosaur sauropod. The layer of epoxy putty (ep) that covers both the sample and the other parts of the bone is removed before molding. 2, The sample is placed on a clay bed, which is filled with more clay until half of the piece is covered. 3, Two clay cones (cc) are built and placed in contact with both the sample and the edge of the container. Some key holes (kh) are put around the sample. The silicone rubber (sr) covers the entire sample and part of the clay bed. 4, When the silicone is cured, a layer of plaster ( $\mathrm{pl}$ ) is created over the silicone to stabilize the sample and then the mold is turned over. A release agent (hard vaseline in this case) is applied on the rubber. 5, The second part of the mold, formed for both silicone rubber and plaster, is done. The two clay cones are removed leaving two sprues (sp) in the mold. 6, The procedure finishes when a high quality cast (left) is obtained from the two-part mold. The original sample (right) can now be processed for thin sectioning. 
instances, the embedding can be done in ordinary silicone buckets. Because direct contact of the sample with the bottom of the container would impedes the formation of a resin rim on the inferior side of the sample, one or two short (around $10 \mathrm{~mm}$ ) 'pillars' of epoxy putty are placed between the sample and the bottom of the container. In some instances (e.g., embedding very small samples), the surface of the sample that faces the bottom of the container must be in contact with the container. Epoxy putty is also useful to fix the sample in the position we need, since small or extant samples may usually move when the resin is poured. This variation on the original procedure minimizes sample loss during thin section preparation (see below). If the sample has an important internal hollow (e.g., empty medullary cavity), this cavity can be filled with epoxy putty.

The sample is embedded in epoxy resin DICAST LY 554 with catalyst DICURE HY 554 in 100:20 proportion. Before the embedding process, both the resin and the catalyst are
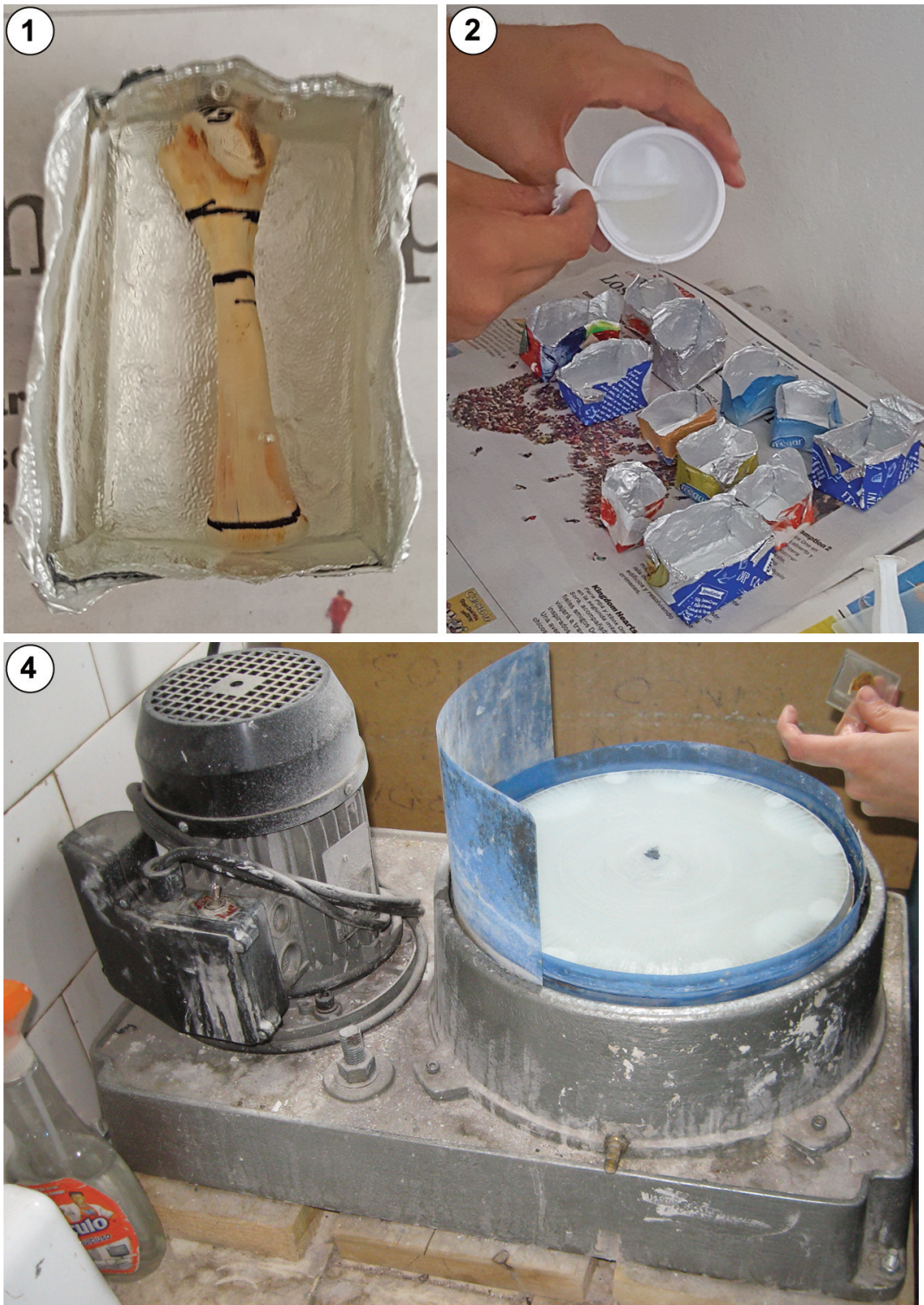
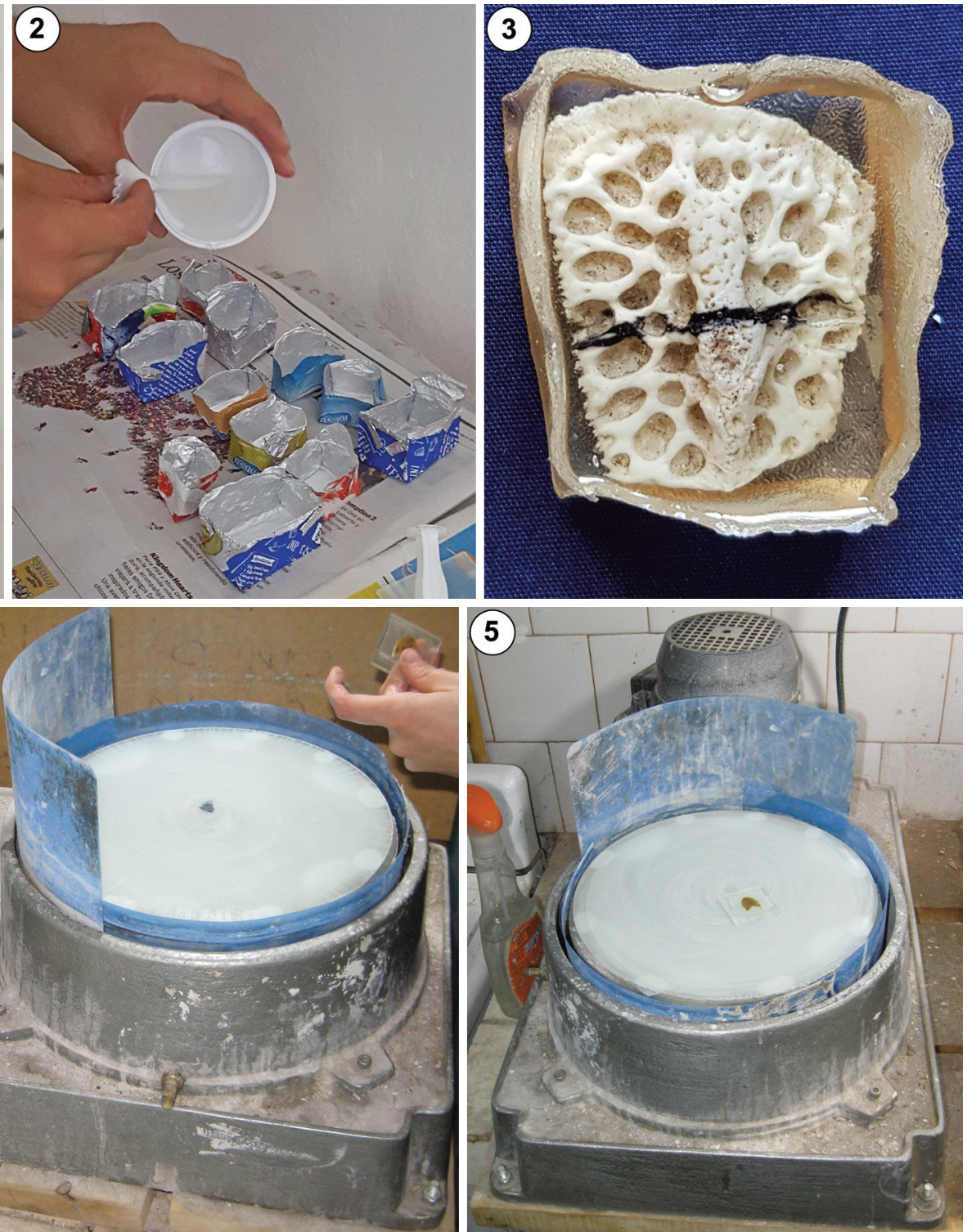

Figure 6. Sample embedding and grinding machine.1, The sample (long bone from an extant turtle) is placed in a container made with coarse aluminum foil paper. 2, Epoxy resin is poured into the containers. 3, Block of hardened resin with sample inside (osteoderm from extant crocodile). 4-5, Homemade lapidary grinding machine. The machine is equipped with an iron cast circular plate, which is covered with glass. 
placed over an electric hot plate at around $40^{\circ} \mathrm{C}$. Once both parts are combined, they are mixed gently during approximately 2 minutes and then poured into the container with the sample. The container is placed on the hot plate for 24 hours. It is very important not to overheat the sample to prevent the resin from hardening too fast, which would produce abundant large bubbles and/or the formation of several cracks in the resin block. Once the resin is completely hardened, the aluminum foil paper is removed from the block by hand and/or using a small knife. In contrast with other published protocols for thin section preparation (e.g., Chinsamy and Raath, 1992; Lamm, 2013), here a vacuum chamber is not employed during the embedding procedure. Use of a vacuum chamber optimizes the procedure because it allows complete infilling with resin of all the internal spaces of the sample. However, the lack of this very important equipment is compensated with the addition of a novel step during the process (i.e., the 'paint and polish' procedure). 'Paint and polish'. After complete hardening of the resin, the resulting block is cut using the high speed diamond cut-off saw. This procedure produces two or more flat surfaces, which are washed with water and detergent solution to remove all oily residues. These surfaces correspond to specific sites from which one wishes to obtain thin sections. The following step is the removal of any surface scratches left by the diamond saw wheel during the cutting process. For this, each surface is polished with abrasive powders (silicon carbide, carborundum), mainly 220 grit (or 180 if the scratches are more marked). The grinding process can be performed by hand or using a grinder machine. The MPCA laboratory is equipped with a homemade lapidary grinding machine which consists of a $27.5 \mathrm{~cm}$ diameter cast iron plate fixed to the central axis of the machine by a conical coupling, for easy cleaning and exchange (Fig. 6.4-5). A circular glass of the same diameter is fixed on this plate using domestic silicone sealant. The glass cover should be periodically replaced due to the continuous erosion of the surface during grinding. The other parts of the machine are built with an alloy of cast aluminum and stainless steel. In addition, it has a $1 \mathrm{HP}, 1500 \mathrm{RPM}$ engine. Thanks to all these characteristics, the plate rotates without producing any imbalance or vibration. If a grinding machine is not available, the process can be done by hand. In this case, the sample is moved over a glass surface covered with abrasive powder; movements in a figure-eight pattern are suggested for better grinding. Irrespective of whether the grinding is done by hand or using a machine, the glass surface must always remain coated with a solution of water and detergent. During the grinding process the same hand-pressure must be applied on the entire surface of the block. The block surface is ground until a smooth surface is obtained. If the original sample maintains the layer of epoxy putty, the grinding process is usually faster, but the glass surface must be repeatedly rinsed during the procedure. After grinding, the samples must be washed with water and detergent and left to air dry.

Because the resin does not penetrate the samples fully during the embedding process, each surface will exhibit some degree of porosity, which varies according to the type of sample. Since infilling of these spaces is strictly necessary for correct mounting of the sample, each surface obtained is 'painted' with epoxy resin DICAST LY 867 combined with catalyst DICURE ${ }^{\oplus}$ HY 867 in a 100:60 proportion (Fig. 7). As explained for the embedding procedure, both resin and catalyst are placed on an electric hot plate before combining them. The epoxy resin DICAST LY 867 has low viscosity, which facilitates the penetration of the sample. Alternatively, a combination of epoxy resin DICAST LY 554 (with its respective catalyst) and alcohol $96^{\circ}$ (50\% of each) may also be effective. This mixture allows the resin to penetrate as much as possible via the bone pores. A spatula or flat spoon is used to apply the prepared mixture. Before the 'painting' procedure, all the blocks are laid on the heat plate with the polished surface facing up and parallel to the horizontal plane. If the polished surface exhibits some degree of inclination because of an irregular shape of the resin block base, a small amount of epoxy putty can be molded and added to achieve the correct position. Once the resin block is correctly positioned on the heat plate, few drops of resin are placed on the block surface and spread evenly. Then any excess of resin is removed using the same flat spoon, and another portion of resin is put onto the block and distributed. This process is repeated several times until the resin penetrates the sample and/or when the resin starts to harden and its viscosity impedes further infilling. Once this step is finished, as much of the excess resin as possible should be removed. 
The resin takes 24 to 48 hours to harden (depending on the type of resin used). At this stage of the process it is necessary to check whether the bone continues to absorb resin, since it is possible that the pores of the bone still need to be filled with resin. If any empty pores remain, the painting process must be repeated. Before repeating the latter process and once the resin has hardened, the surface of the block must be ground with silicon carbide, this time
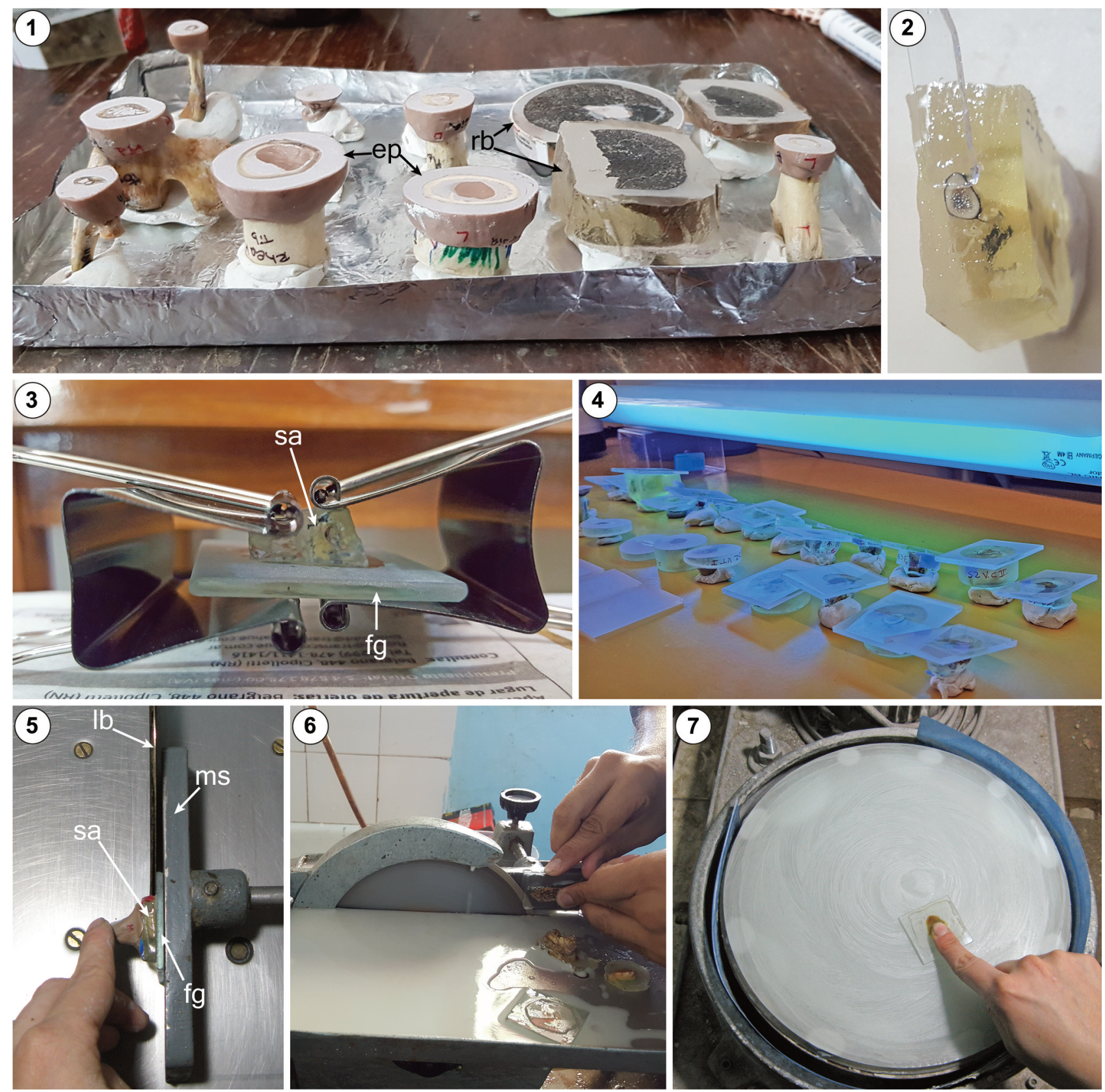

Figure 7. 'Painting' procedure, sample mounting and sectioning. 1-2, Before 'painting', all the samples are placed with the polished surface facing up and parallel to 1 , the horizontal plane, and then 2, 'painted' with epoxy resin using a flat spoon. Note that whereas some of the samples are included within a resin block (rb) others still maintain the original layer of epoxy putty (ep). 3-4, The mounting can be done using 3, epoxy resin, or 4, ultraviolet curing glue. In the first case, the mounted sample (sa) is clamped to the frosted glass (fg) using metal clips. $\mathbf{5 - 6}$, To obtain the thin section, the mounted sample is manually moved over the flat surface of the movable support (ms) toward the lapidary blade saw (Ib). 7, The thickness of the obtained sample is reduced using the lapidary grinding machine and/or by hand. 
using 400 grit, to remove the excess resin deposited during the painting process. Once again, after verifying that the surface has no marks or imperfections, the block is left to air dry. The 'paint and polish' procedure is repeated as many times as necessary according to the degree of porosity of the sampled specimen. The process is finished when the bone surface does not absorb more resin. Once the resin has infiltrated the surface entirely, a final polishing using 400 grit silicon carbide abrasive powder is done by hand or using the grinding machine until the surface becomes completely flat, smooth, and free from scratch marks.

As previously mentioned, for those cases in which the specimen is extremely small (about $5 \mathrm{~mm}$ thickness or less) and the sample is not placed over a 'pillar' of epoxy putty, the resin block is not cut with the diamond cut-off saw. Instead, the surface that corresponds to the bottom of the container is ground until reaching the level of the desired thin section. Once this level is reached, the 'paint and polish' procedure is carried out. This variation on the process minimizes the loss of sample material due to use of the diamond saw. In the case of large-sized samples, before the 'paint and polish' procedure, the sectioned parts of the sample are divided into smaller pieces, which will be individually processed. The number of segments depends on the size and shape of the bone. For example, for a complete femoral diaphysis of a small bodied sauropod such as Saltasaurus (152 x $63 \mathrm{~mm})$, three sections (one in lateromedial direction, two in anteroposterior direction) were cut in each half of the sample, obtaining twelve fragments that fit well in $60 \times 500$ $\mathrm{mm}$ petrographic slides.

Mounting. The processed samples are mounted on frosted glass slides. Glass slides are ordered from glassware suppliers with dimensions that depend on the sample size. We usually employ slides that are $3 \mathrm{~mm}$ thick and range from $40 \times 40 \mathrm{~mm}$ to $90 \times 50 \mathrm{~mm}$. Square-shaped slides facilitate handling of the sample during the grinding process. The
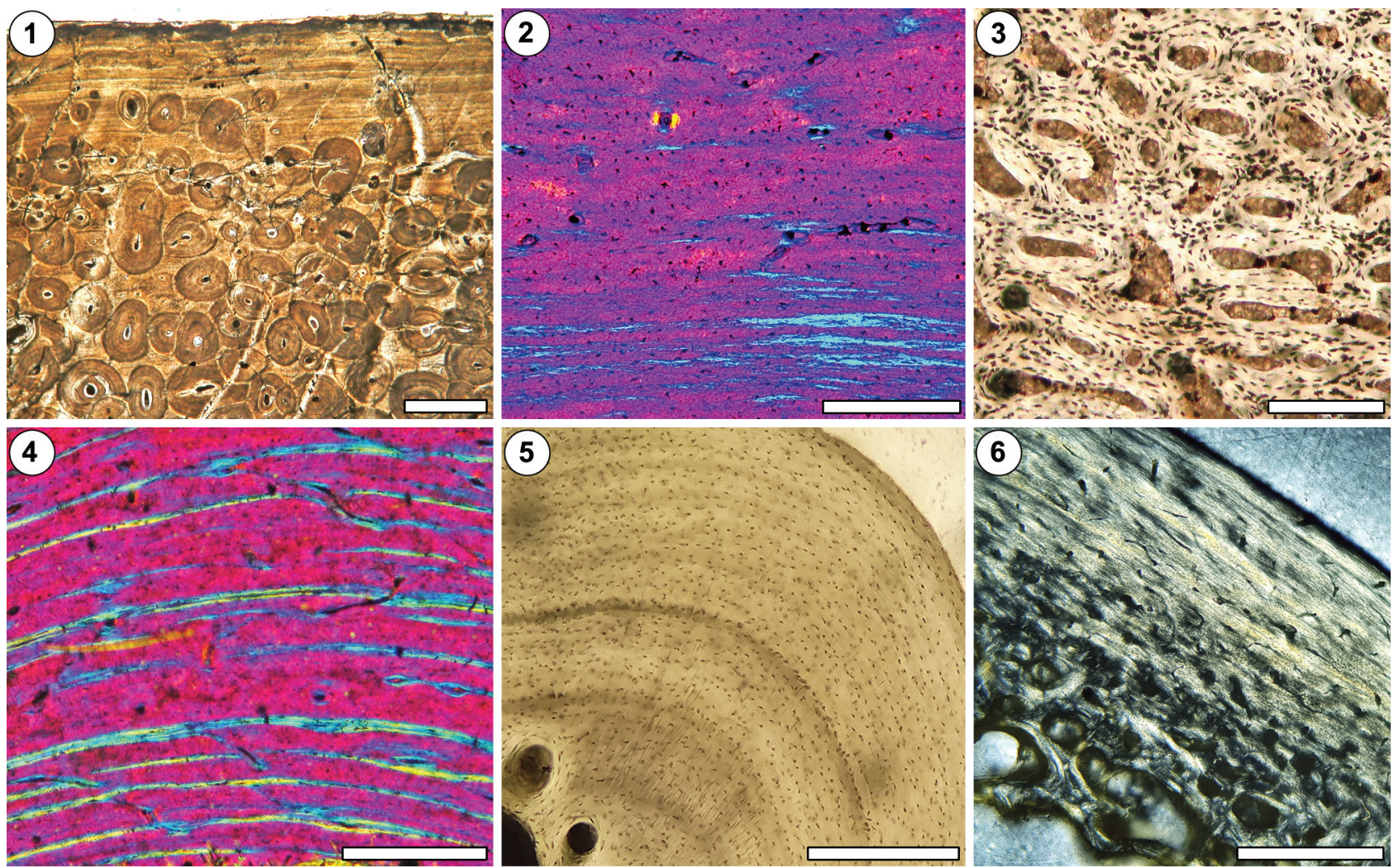

Figure 8. Examples of thin sections obtained by the method proposed here. 1, Theropod dinosaur rib. 2, Fossil pleurodiran turtle long bone. 3, Sauropod dinosaur long bone. 4, Pterosaur long bone. 5, Extant pleurodiran turtle long bone. 6, Extant crocodilian long bone. Scale bars= 0.2 $\mathrm{mm}(2,3,4), 0.5 \mathrm{~mm}(5), 1 \mathrm{~mm}(6)$. 
glass slides are frosted in the grinding machine using carbide powder, 80 or 120 grit. A frosted surface notably increases the contact area between the glass, the block and the substance used for mounting. To ensure correct frosting of the slide, the latter must be rinsed with a brush and air dried. It is advisable to polish the sides and corners of the glass for greater safety when handling them. Once a frosted surface is obtained, both the block and the slide are cleaned with alcohol and dried with tissue paper to remove all remaining dust residues. If the piece will be mounted with resin, the block and the glass should be placed on the heat plate to ensure that both components are at the same temperature.

Mounting can be performed using epoxy resin DICAST LY 867 combined with its catalyst or with ultraviolet curing glue TRABASIL NR2 (Fig. 7). If resin is used, it must be handled on the heat plate (as previously mentioned). A few drops of resin need to be placed both on the polished surface of the block and on the frosted side of the slide; a few seconds later both sides are attached together. Hand-pressure should be applied, always taking care to avoid bubble formation. After ascertaining that there are no bubbles left, the mounted sample is clamped to the glass slide by means of one or more metal clips (Fig. 7.3). If such clips cannot be used, the sample must be put on a flat surface with the block facing up. The glass with the block must be in horizontal position, because during the hardening process the block might move under the glass. The mounted sample is left on the heat plate for around 24 hours.

If ultraviolet curing glue is used, the whole process must be done under an ultraviolet light lamp (UV). In this case, a few drops should be placed on the frosted side of the slide, always avoiding bubble formation. The glass slide is placed with the side opposite to the frosted surface facing the UV light source. We use a custom 40W lamp. Curing this glue takes 30 seconds (partial hardening) to 3 hours (total hardening).

Whether the mounting is done with resin or ultraviolet curing glue, the block should be placed as centrally as possible, as this will facilitate the work during grinding. The ultraviolet curing glue is particularly useful for extant bones (the sample sometimes peels off when resin is used in these cases).
Thin sectioning. The mounted sample is cut with the highspeed diamond cut-off saw. This equipment has a movable support with a flat surface that is aligned in parallel with the diamond saw (Figs. 1.3 and 7). This surface allows maintaining a precise cutting plane during sectioning. The free surface of the glass is placed against the flat surface of the movable support leaving a distance of approximately $2 \mathrm{~mm}$ between the lapidary blade and the glass surface where the sample is mounted. Then, the support is fixed using a screw built into the machine. To obtain the thin section, the mounted sample is manually moved over the flat surface of the machine toward the lapidary blade saw. This procedure allows obtaining a section that is about $2 \mathrm{~mm}$ thick or less, which is still too thick for histological analysis. This sample is then ground and polished with silicon carbide powder of decreasing coarseness, usually from 180 to 220 grit, using the above mentioned custom grinding machine. In addition, some manual grinding should be done to make the surface thinner. The final grinding is done with 400 to 800 grit powder. Due to variations in fossil preservation, the final section thickness is not equal in all the samples; thus, the final grinding should be done cautiously and the thin section should be checked regularly under petrographic microscope.

\section{FINAL CONSIDERATIONS}

The protocol detailed here has been developed and used by us for the last few years. This procedure was used to generate thin sections of both extant and extinct vertebrates. Although the procedure for acquisition of thin sections is mainly the same for samples taken from either extant or extinct vertebrates, these two types of materials present some differences in terms of the type of glue used and the repetition of some steps (i.e., the 'paint' and polish is usually repeated more times for extant vertebrate samples). This protocol has been improved following the advice of colleagues and the incorporation of new equipment and supplies. As previously mentioned, we are aware that the procedure can still be enhanced by addition of more specific equipment (e.g., vacuum chamber). In any case, given the good quality of the sections obtained (Fig. 8), we consider that the protocol is suitable enough for any paleohistological laboratory, particularly those with newly established research groups and/or restricted funding. 


\section{ACKNOWLEDGMENTS}

We thank the PE-APA Editorial board, particularly J. L. Carballido, for the invitation to submit this contribution to the journal. D. Codega and J. Kaluza provided helpful information about some steps of the protocol. We thank C. Muñoz for allowing the creation of the Paleohistological Laboratory in the Museo Provincial Carlos Ameghino. A. Martínez provided relevant data about the employed equipament. C. Morgan revised the English style of the manuscript. Sci Hub and Wikipaleo groups for sharing bibliography. L. Salgado and C. Apaldetti provided constructive reviews.

\section{REFERENCES}

Chinsamy, A. 1990. Physiological implications of the bone histology of Syntarsus rhodesiensis (Saurischia, Theropoda). Paleontologia Africana 27: 77-82.

Chinsamy, A. 1993. Bone histology and growth trajectory of the prosauropod dinosaur Massospondylus carinatus Owen. Modern Geology 18: 319-329.

Chinsamy, A. 1995. Ontogenetic changes in the bone histology of the Late Jurassic ornithopod Dryosaurus lettowvorbecki. Journal of Vertebrate Paleontology 15: 96-104.

Chinsamy, A. and Raath, M.A. 1992. Preparation of fossil bone for histological examination. Palaeontologia Africana 29: 39-44.

Company, J. 2011. Bone histology of the titanosaur Lirainosaurus astibiae (Dinosauria, Sauropoda) from the Latest Cretaceous of Spain. Naturwissenschaften 98: 67-78.

Curry, K.A. 1999. Ontogenetic histology of Apatosaurus (Dinosauria, Sauropoda): new insights on growth rates and longevity. Journal of Vertebrate Paleontology 19: 654-665.

Dupret, V., Sánchez, S., Goujetc, D., Tafforeaub, P., and Ahlberg, P.E. 2010. Bone vascularization and growth in placoderms (Vertebrata): The example of the premedian plate of Romundinastellina $\emptyset$ rvig, 1975. Compets Rendus Palevol 9: 369-375.

Enlow, D.H. and Brown, S.O. 1956. A comparative histological study of fossil and recent bone tissue. Part I. Texas Journal of Science 8: 405-443.

Erickson, G.M., Curry-Rogers, K., Varrichio, D.J., Norell, M.A., and Xu, X. 2007. Growth patterns in brooding dinosaurs reveals the timing of sexual maturity in non-avian dinosaurs and genesis of the avian condition. Biology Letters 3: 558-561.

Erickson, G.M., Curry-Roger, K., and Yerby, S.A.2001. Dinosaurian growth patterns and avian rapid growth rates. Nature 412: 429433.

Hayashi, S., Carpenter, K., and Suzuki, D. 2009. Different growth patter between the skeleton and osteoderms of Stegosaurus (Ornithischia, Thyreophora). Journal of Vertebrate Paleontology 29: 123-131.

Klein, N. and Sander, P.M. 2007. Bone histology and growth of the prosauropod dinosaur Plateosaurus engelhardtiVon Meyer, 1837 from the Norian bone beds of Trossingen (Germany) and Frick (Switzerland). Special Papers in Palaeontology 77: 169-206.

Klein, N. and Sander, P.M. 2008. Ontogenetic stages in the long bone histology of sauropod dinosaurs. Paleobiology 34: 247-263.

Lamm, E.T. 2013. Preparation and Sectioning of Specimens. In: K. Padian and E.T. Lamm (Eds.), Bone Histology of Fossil Tetrapods: Advancing Methods, Analysis and Interpretation. University of California Press, Berkeley, p. 55-160.

Lee, A.H. and Werning, S. 2008. Sexual maturity in growing dinosaurs does not fit reptilian growth models. PNAS 105: 582587.

Lehman, T.M. and Woodward, H.N. 2008. Modeling growth rates for sauropod dinosaurs. Paleobiology 24: 624-281.

Luna, C.A., Cerda, I.A., Zurita, A.E., González, R., Prieto, M.C., Mothé, D., and Avilla, L.S. 2018. Distinguishing Quaternary glyptodontine cingulates in South America: How informative are juvenile specimens? Acta Palaeontologica Polonica 63: 159-170.

Marín-Moratalla, N., Jordana, X., and Köhler, M. 2013. Bone histology as an approach to providing data on certain key life history traits in mammals: implications for conservation biology. Mammalian Biology 78: 422-429.

Martínez-Maza, C., Alberdi, M.T., Nieto-Díaz, M., and Prado, J.L. 2014. Life-history traits of the Miocene Hipparion concudense (Spain) inferred from bone histological structure. PLOS ONE 9: e103708. Doi:10.1371/journal.pone.0103708.

Mukherjee, D. 2018. An improvised core-drilling technique and a new device for osteohistology of fossil bones: implementation on a Jurassic sauropod dinosaur from India. Journal Geological Society of India 91: 295-300.

Padian, K., Horner, J.R., and de Ricqlès, A. 2004. Growth in a small dinosaur and pterosaurs: the evolution of archosaurian growth strategies. Journal of Vertebrate Paleontology 24: 555-571.

Sánchez, S., Dupret, V., Tafforeau, P., Trinajstic, K.M., Ryll, B., Gouttenoire, P-J., Wretman, L., Zylberberg, L., Peyrin, F., and Ahlberg, P. 2013. 3D microstructural architecture of muscle attachments in extant and fossil vertebrates revealed by synchrotron microtomography. PLOS ONE 8: e56992.

Sander, P.M. 2000. Long bone histology of the Tendaguru sauropods: implications for growth and biology. Paleobiology 26: 466-488. Doi: 10.1371/journal.pone.0056992

Sander, P.M., Mateus, O., Laven, T., and Knötschke, N. 2006. Bone histology indicates insular dwarfism in a new Late Jurassic sauropod dinosaur. Nature 441: 739-741.

Steel, L. 2008. The palaeohistology of pterosaur bone: an overview. Zitteliana 28: 109-125.

Stein. K., Csiki, Z., Curry-Rogers, K., Weishampel, D.B., Redelstorff, R., Carballido, J.L., and Sander, P.M. 2010. Small body size and extreme cortical bone remodeling indicate dwarfism in Magyarosaurus dacus (Sauropoda, Titanosauria). Proceeding of the Natural Academy of Science of the United States of America 107: 9258-9263.

Stein, K. and Sander, P.M. 2009. Histological core drilling: a less destructive method for studying bone histology. In: M.A. Brown, J.F. Kane, and W.G. Parker (Eds.), Methods In Fossil Preparation: Proceedings of the first Annual Fossil Preparation and Collections Symposium. Petrified Forest, p. 69-80.

Varricchio, D.J. 1993. Bone microstructure of the Upper Cretaceous theropod dinosaur Troodon formosus. Journal of Vertebrate Paleontology 13: 99-104.

Werning, S. 2012. The ontogenetic osteohistology of Tenontosaurus tilletti. PLoS ONE 7: e33539. Doi:10.1371/journal.pone.0033539

Woodruff, D.C., Fowler, D.W., and Horner, J.R. 2017. A new multifaceted framework for deciphering diplodocid ontogeny. Palaeontologia Electronica 20.3.43A: 1-53.

doi: 10.5710/PEAPA.07.04.2020.314

Recibido: 7 de febrero 2020

Aceptado: 7 de abril 2020 